\title{
Isn't It Ironic? An Electrophysiological Exploration of Figurative Language Processing
}

\author{
Stefanie Regel, Thomas C. Gunter, and Angela D. Friederici
}

\begin{abstract}
Although the neurocognitive processes underlying the comprehension of figurative language, especially metaphors and idioms, have been studied extensively, less is known about the processing of irony. In two experiments using event-related brain potentials (ERPs), we examined the types of cognitive processes involved in the comprehension of ironic and literal sentences and their relative time course. The experiments varied in modality (auditory, visual), task demands (comprehension task vs. passive reading), and probability of stimulus occurrence. ERPs consistently revealed a large late positivity (i.e., P600 component) in the absence of an
\end{abstract}

\section{INTRODUCTION}

Communicating with another individual allows us not only to exchange information and to express attitudes but also to realize various intentions. However, communication is often not straightforward, as many aspects of what we are saying are not explicitly stated. This is especially the case for figurative language such as irony or metaphors. In order to comprehend a figurative sentence as the speaker intends it, an in-depth interpretation beyond the literal sentence meaning is required. When encountering irony, for example, contextual and pragmatic information is crucial to understand the implied figurative meaning denoting a speaker's belief or attitude. From this perspective, irony is a very interesting phenomenon for investigating the processing of evaluative utterances in social communication. For instance, if someone says "That's fantastic," he or she may not wish to convey the literal meaning of the sentence at all (i.e., positive estimation) but instead, an ironic meaning, for example, on receiving a parking ticket (i.e., disappointment).

Verbal irony is a common and frequently occurring figure of speech (see Holtgraves, 2001; Gibbs, 1994) typically used as an attention-getting device or politeness strategy enabling the speaker to negate something by using an affirmative expression (Brown \& Levinson, 1978). Although there are various views on verbal irony, in general, it can be defined as a figure of speech that implies

Max-Planck-Institute for Human Cognitive and Brain Sciences, Leipzig, Germany
N400 component for irony compared to equivalent literal sentences independent of modality. This $\mathrm{P} 600$ was shown to be unaffected by the factors task demands and probability of occurrence. Taken together, the findings suggest that the observed P600 is related to irony processing, and might be a reflection of pragmatic interpretation processes. During the comprehension of irony, no semantic integration difficulty arises (absence of N400), but late inferential processes appear to be necessary for understanding ironic meanings (presence of P600). This finding calls for a revision of current models of figurative language processing.

a different, and often opposite, meaning of what has been stated literally.

Figurative language comprehension has been described by different approaches varying in the assumptions on the time course of irony processing. The standard pragmatic model (transferred from the work of Searle, 1979; Grice, 1975) suggests that the literal meaning of an ironic sentence must initially be accessed and rejected, resulting in processing difficulty when integrating the literal meaning with prior contextual information. Further processing involving inference is therefore assumed to be necessary in order to derive the contextually appropriate figurative meaning. By contrast, the direct access model (Gibbs, 1994, 2002) is based on the assumption that the processing of lexical-semantic information interacts with contextual information very early on. On the basis of rich supportive contexts, the parser will immediately access the contextually relevant meaning, allowing a direct understanding of irony. ${ }^{1}$ A parallel model merging the theoretical approaches already mentioned is formulated in the graded salience hypothesis (Giora, 1997, 2002). This model assumes an initial processing of salient meanings (i.e., the most conventional and frequent meanings of a word), whereby lexical access of the mental lexicon is independent of contextual information as well as figurativity of sentences. The most salient meanings of words or expressions will be accessed first, whereas nonsalient meanings are assumed to require further processing. In the case that the salient meanings activated are contextually incompatible, additional processes become necessary for processing appropriate nonsalient meanings. Contextual information 
is assumed to be processed in parallel, but will neither interact with lexical processes nor have a selective influence. Thus, the graded salience hypothesis predicts semantic integration difficulty for nonsalient figurative meanings before appropriate sentence meanings can be accessed. In this respect, this model resembles the standard pragmatic model.

Regarding the processing of irony, evidence for the discussed models mainly stems from behavioral studies that compared reading or reaction times for the processing of ironic and literal sentences. In a study by Dews and Winner (1999), longer reaction times were found for sentences that had an ironic meaning compared to their equivalent nonironic meaning. These results were interpreted in favor of the standard pragmatic model because the processing of the literal meaning of an ironic sentence was assumed to result in longer reaction times for the comprehension of irony. In contrast, no differences in reading times were seen for sarcastic ${ }^{2}$ and nonsarcastic utterances such as "You're a fine friend" (Gibbs, 1986). Although this study provides evidence for the assumption of the direct access view, findings by Giora and Fein (1999) showed that irony comprehension depends on the salience of figurative meanings supporting processing mechanisms described by the graded salience hypothesis. In the study by Giora and Fein, conventional forms of irony (e.g., "Very funny") were processed in a similar manner as literal utterances. In contrast, nonconventional forms of irony showed longer response times than literal sentences for lexical decisions after $150 \mathrm{msec}$, but no longer did so for lexical decisions after $1000 \mathrm{msec}$. However, when and how the comprehension of irony diverges from literal language cannot precisely be defined by behavioral measures.

Investigating the exact timing of irony comprehension can be accomplished using event-related brain potentials (ERPs), which are time-sensitive measurements in the order of milliseconds. This imaging method also allows a differentiation between the neurocognitive processes underlying comprehension present at a particular time. A negative-going brain potential with a centro-parietal scalp distribution and a peak latency of around $400 \mathrm{msec}$ poststimulus onset is known as an N400 component. This ERP component is reliably elicited by semantic-pragmatic anomalies, and has been suggested to reflect semantic integration difficulty (for reviews, see Kutas, Van Petten, \& Kluender, 2006; Kutas \& Federmeier, 2000). Larger N400 amplitudes were seen for outright semantic violations (Kutas \& Hillyard, 1980) as well as for words that are difficult to integrate into sentences and discourses (Van Berkum, Brown, Hagoort, \& Zwitserlood, 2003; Brown \& Hagoort, 1993).

Words that are incongruous on the discourse level also evoked an N400 that was similar to N400 effects seen for sentential semantic violations (Van Berkum, Hagoort, \& Brown, 1999). Modulations of the N400 amplitude were also reported for sentences varying in semantic expectancy. ${ }^{3}$
The lower the semantic expectancy of the sentence-final word, the larger the N400 (Kutas \& Hillyard, 1984). With regard to figurative language comprehension, N400 effects were often seen in response to metaphors (Coulson \& Van Petten, 2002, 2007; Tartter, Gomes, Dubrovsky, Molholm, \& Stewart, 2002; Pynte, Besson, Robichon, \& Poli, 1996), or proverbs and idioms (Ferretti, Schwint, \& Katz, 2007; Laurent, Denhieres, Passerieux, Iakimova, \& Hardy-Bayle, 2006). Cornejo et al. (2007) found an N400-like component for irony, which depended on the interpretative strategy applied. This N400-like effect emerged during holistic processing (i.e., focusing on sentence plausibility) but not during analytic processing (i.e., judging sentence congruency). However, because this study investigated the effects of different interpretative strategies, it is still unclear how irony is processed in a natural comprehension setting in the absence of any strategy manipulations.

Another language-related ERP component is a centroparietally distributed late positivity termed P600. This brain potential is considered to reflect syntactic processes associated with structural reanalysis or repair (Osterhout \& Mobley, 1995; Osterhout, Holcomb, \& Swinney, 1994), syntactic integration (Kaan, Harris, Gibson, \& Holcomb, 2000), or enhanced syntactic complexity (Friederici, Hahne, \& Saddy, 2002). Since the earliest reports of this "syntaxrelated" ERP component, there has been debate and controversy regarding what underlying processes the P600 is assumed to reflect. The extent to which this brain potential is exclusively sensitive to syntactic information has been called into question, as P600 amplitude has been found to be modulated by various kinds of information other than syntactic information. The P600 has been suggested to reflect late integration processes of various information types (Friederici \& Weissenborn, 2007; Friederici, Gunter, Hahne, \& Mauth, 2004), or alternatively was taken as an index of generalized mapping (Bornkessel-Schlesewsky \& Schlesewsky, 2008) as well as domain-general processes such as the concept of monitoring (Kolk, Chwilla, van Herten, \& Oor, 2003; Coulson, King, \& Kutas, 1998). Most recently, the P600 component has been regarded as a reflection of reanalysis and interpretation processes based on semantic information (Ericsson, Olofsson, Nordin, Rudolfsson, \& Sandstrom, 2008).

These functional interpretations are based on the observation that the P600 was modulated by semantic expectancy (Gunter, Friederici, \& Schriefers, 2000; Gunter, Stowe, \& Mulder, 1997), by probability of stimulus occurrence (Coulson et al., 1998), and, moreover, by thematic and semantic-pragmatic anomalies (Ericsson et al., 2008; Vissers, Chwilla, \& Kolk, 2006; Kuperberg, Holcomb, et al., 2003; Gunter et al., 2000). For example, a late positivity was elicited by utterances such as "The cat that fled from the mice" that were syntactically correct but contained a semantic reversal anomaly (van Herten, Kolk, \& Chwilla, 2005; Kolk et al., 2003). These late positivities in response to thematic role (animacy) violations have often been referred to as "semantic P600" because they were evoked 
in the absence of syntactic violations (Nieuwland \& Van Berkum, 2005; Hoeks, Stowe, \& Doedens, 2004; Kuperberg, Sitnikova, Caplan, \& Holcomb, 2003). These recent findings suggest that the sensitivity of the P600 is not confined to one specific type of linguistic information, but reflects different types of processing problems.

\section{EXPERIMENT 1}

The present experiment addresses the question of when and how contextual information is integrated during the comprehension of verbal irony. Of particular interest is the question of whether the literal meaning of the sentence needs to be fully processed before the figurative meaning can be accessed. Therefore, subjects were presented with target sentences that were designed to be interpreted in either a literal or an ironic manner with respect to the preceding discourse context. Whenever the target sentences refer to the discourse contexts in a contradictory way, their meaning is ironic. If this is not the case, their meaning is literal.

With regard to the discussed models of figurative language comprehension, the following predictions can be made. According to the standard pragmatic model (Searle, 1979; Grice, 1975), the literal meaning of an ironic utterance should be accessed first. This would lead to difficulty in semantic processing during the integration of the critical (i.e., sentence-final) word with the prior contextual information. Thus, according to this model, an irony-related N400 component reflecting difficulty in semantic integration is predicted. With respect to postulated later inferential processes, the emergence of an additional late positivity is also possible. Because a number of recent studies report "semantic P600" effects in response to various semantic and thematic anomalies (cf. Introduction), these late processes might be reflected in a modulation of the P600. With respect to the graded salience hypothesis (Giora, 1997, 2002), a similar ERP pattern consisting of an N400 followed by P600 would be expected. This model predicts processing costs for low salient figurative meanings - as this is the case for irony presented in the current experiment-during semantic integration and appropriate sentence interpretation. The direct access model (Gibbs, 1994, 2002) would predict the absence of any ERP effects associated with integration difficulty (i.e., absence of an N400 and P600) as this model assumes that there is no difficulty processing irony when it is embedded in supportive contexts.

An additional question examined in Experiment 1 is whether prosodic information can affect irony comprehension, and whether it facilitates the detection of nonliteral interpretations. Among a variety of verbal and paraverbal characteristics accompanying irony, prosody has been identified as an important cue for the understanding of ironic and sarcastic speech (Rockwell, 2007; Attardo, Eisterhold, Hay, \& Poggi, 2003). Sarcasm, which is closely related to irony, was characterized by lower fundamental frequency (F0), longer duration, and higher intensity in a rating study. Except for finding higher frequency values, Anolli, Ciceri, and Infantino (2000) likewise reported longer duration and higher intensity for ironic speech compared to literal speech. The findings of these studies imply that irony is often characterized by particular prosodic features which vary to some extent (e.g., in F0).

Based on these findings, the current study aims to examine the role of prosody in the comprehension of irony by manipulating prosodic characteristics of the target sentences (i.e., target sentences were spoken with normal or ironic prosody). If prosodic information has an impact on ironic language, interactions between prosody and irony will be found. Because there is no previous ERP evidence on the effects of prosody on figurative language comprehension, it cannot be precisely hypothesized what the interaction of prosody with irony will look like. Yet, in the case that prosodic information plays a role in detecting irony, we predict an impact of prosody during semantic processing (i.e., between 300 and $500 \mathrm{msec}$ ). If there is such an effect of prosody, the potential N400 for irony will vary in amplitude as a function of prosody, with a reduced amplitude for sentences spoken with ironic prosody compared to normal prosody.

\section{Methods}

\section{Participants}

Forty native German-speaking students (22 women, mean age $=24.7$ years, $S D=3.12$ ) participated in the experiment. All were right-handed, had normal or corrected-tonormal vision, and had no hearing impairment. Subjects were paid for their participation.

\section{Stimulus Material}

The stimulus material was created for testing and contained 120 experimental sentences, which were manipulated with respect to pragmatics and prosody. Stimuli consisted of a context composed of three sentences followed by the target sentence. Each semantically and syntactically identical target sentence appeared in two different contexts with differing pragmatic meanings (see Table 1). A target sentence contained an ironic meaning when it contradicted the foregoing discourse context. Irony mostly contained an opposite meaning of what could be literally expected as an adequate reply in this context. By contrast, a target sentence retained its literal meaning when it corresponded with the preceding context (i.e., biasing towards a literal sentence interpretation). The final word in the target sentence was critical for respective sentence interpretations because, at this position, it became obvious whether the sentence conflicted with the context or not. With regard to the contents of the stimuli, discourse topics spanned a 
Table 1. Example of Stimuli (Approximate Translation from German)

Ironic Discourse Examples

(1) During a concert, Franz detects some mistakes in the sonata. He tries to ignore them, but soon he hears another one. He looks down at the orchestra and thinks:

"These artists are gifted."

(2) Nina decided to cook dinner. As she couldn't find the recipe, she put in plenty of spices. When her boyfriend tasted the spicy dish, he was startled, put his spoon aside and said:

"That's really bland."

(3) Karolin tells her friend very proudly that she studied for a whole hour today. Her friend worked for many hours and couldn't understand her. She sneeringly commented to Karolin:

"You should take a break."
Nonironic Discourse Examples

(1) Adrian likes music a lot, especially classical music. During the "Bachfest" he is attending an enchanting concert. In ecstasy, he starts to applaud at the end and says to his neighbor:

"These artists are gifted."

(2) Tom was quite hungry and went into the kitchen to see what he could find there. He discovered a pan full of vegetables and immediately tasted it. However, the dish wasn't tasty and so he said:

"That's really bland."

(3) Monika became very tired from studying the whole day. She could only hardly concentrate on what she was reading. A friend sitting beside her noticed Monika's weariness and advised her:

"You should take a break." broad range of informal daily situations, such as living together, being at lunch, or visiting someone/something. The relationship between speakers and listeners in these discourse examples was mainly that of friends, relatives, or a couple. The gender of speaker and listener was mostly balanced.

For the prosodic manipulation, a female professional speaker spoke all target sentences with ironic and normal intonation. Target sentences and discourse contexts were spoken continuously as complete discourse. Recordings were taped with a DAT recorder and digitized at a sampling rate of $48.6 \mathrm{kHz}$. In order to create prosodic-pragmatic violation conditions, discourse contexts and target sentences were cross-spliced. Target sentences with normal prosody were spliced to discourse contexts with a bias toward an ironic interpretation, and sentences with ironic prosody were spliced to nonironic discourse contexts. Thus, contexts and prosody were fully crossed, leading to four experimental conditions and a total set of 480 items.

\section{Pretests of Stimulus Material}

To ensure that potential target sentences were comparable in their semantic expectancy and were interpreted as ironic or nonironic, a cloze procedure and a rating study were conducted before the 120 experimental items were chosen. By means of a cloze probability test (Taylor, 1953), the expectancy of respective target sentence meanings was determined. As ironic instances were neither conventional nor idiomatic, this pretest was necessary to preclude processing difficulty due to differences in semantic expectancy between ironic and nonironic sentences. Therefore, 175 potential items (i.e., the three context sentences followed by the target sentence) were presented with the final word of the target sentence omitted. Participants had to complete the sentences with the most appropriate word. The final word in the target sentence was removed using a speech wave editor (CoolEdit2000), whereby we ensured that no coarticulation effects were present. All items were pseudorandomized across two lists so that each version of the sentence appeared only once in a list.

Twenty-eight students ( 12 women, mean age $=24.0$ years, $S D=2.74$ ) participated in the cloze test. It should be noted that participants were presented with an ironic and nonironic example so that they knew that some of the items were meant ironically. Target sentences were included as experimental items whenever sentence completions for ironic sentences corresponded in meaning to sentence completions for nonironic sentences. Both sentences did not have to be completed with the same word but with words that were semantically related. In total, 120 items with a cloze probability of at least $90 \%$ were obtained. Ironic sentences had an expectancy of $91 \%(S D=11.29)$ and nonironic sentences, $96.7 \%(S D=6.88)$. Semantic expectancy of ironic target sentences was still approximately $5 \%$ lower than their nonironic equivalents [paired $t$ test on items: $t(119)=28.25, p<.001]$.

To verify that experimental items were perceived as ironic or nonironic, an additional rating study was conducted on the 120 items. Twenty participants (10 women, mean age $=23.9$ years, $S D=3.28$ ) who did not participate in the cloze procedure took part in this rating study. All items were pseudorandomized and balanced across two lists. Participants were asked to listen to the discourses and to rate the target sentences on a 5-point scale from 1 (nonironic) to 5 (very ironic). A clear difference between ratings of ironic and nonironic target sentences was observed. On average, ironic sentences were rated as highly ironic with 4.3, and nonironic sentences as rather 
Table 2. Results from Acoustic Analyses of the Experimental Material for Differences in Duration (msec)

\begin{tabular}{lcrrr}
\hline & & Mean Values of Duration (msec) & \\
\cline { 2 - 4 } Segment & Mean Ironic Prosody (Mip) & Mean Normal Prosody (Mnp) & $t$ & .00 \\
\hline Sentence & 1608 & 1555 & 7.18 & .07 \\
Beginning & 225 & 212 & 3.14 & .00 \\
Ending & 600 & 570 & 9.67 \\
\hline
\end{tabular}

Significant effects are marked in italics. Mip = mean values for ironic prosody; Mnp $=$ mean values for normal prosody.

nonironic with 1.5 [paired $t$ test on items: $t(119)=2187.9$, $p<.001]$.

\section{Acoustic Analyses}

To describe the prosodic parameters of ironic and nonironic prosody, acoustic analyses were performed using Praat (version 4.3.07; www.praat.org). Duration, fundamental frequency (F0), and intensity were extracted for complete target sentences, as well as separately for the sentence beginning and the sentence ending. These three variables were chosen because they are strongly associated with perceptually recognizable prosodic qualities. Time points of onset and offset for each of these segments were set by close listening and visual inspection of the speech signal. Differences between ironic and normal prosodic realizations were tested using paired $t$ tests with prosody as the within-subject factor.

The duration of each speech segment was analyzed by subtracting the onset from the offset. Differences in duration were found for the complete sentence, as well as for both the sentence beginning and ending (see Table 2). For all speech segments, ironic prosody was characterized by a longer duration. In addition, the duration of entire discourses was analyzed to control for potential length effects. The discourses had an average duration of $13282 \mathrm{msec}$, which did not differ significantly across both context types $[t(238)=1.43, n s]$.

Fundamental frequency (F0) values were extracted at the onset, minimum, maximum, and offset of each segment as these values reveal the most important characteristics of the F0 contour. A frequency range between 75 and
$500 \mathrm{~Hz}$ was chosen for the analysis. Differences in F0 were found at the minimum of the complete sentence and particularly at the sentence ending, as well as at the offset of the sentence beginning (see Table 3). Hence, ironic prosody was characterized by a higher pitch at the target sentence beginning and a lower pitch minimum at the target sentence offset.

The intensity contour was analyzed starting with an intensity minimum of $60 \mathrm{~dB}$. Differences in intensity were observed for all speech segments, suggesting a slightly lower intensity of ironic prosody that was constantly present (see Table 4).

In sum, prosodic analyses of the target sentences showed that ironic prosody differed in its perceptual features from normal prosody. Ironic prosody was characterized by sentenceinitial and sentence-final lengthening, both higher pitch maximum at the sentence beginning but lower pitch minimum at its offset, and permanently lower intensity.

\section{Procedure}

Participants were seen individually in a 45 -min session during which they were seated in a dimly lit, soundproof cabin facing a computer screen at a distance of approximately $100 \mathrm{~cm}$. They were asked to listen attentively to the discourses and to reply to a comprehension task as accurately as possible, thereby ensuring that participants attended to the discourses. For this task, a test statement that had to be judged with "yes" or "no" (e.g., "Franz enjoyed the concert") was presented visually. Participants had to decide whether the statement reflected the foregoing discourse contexts. Half of the statements were

Table 3. Results from Acoustic Analyses of the Experimental Material for Differences in Fundamental Frequency (Hz)

\begin{tabular}{|c|c|c|c|c|c|c|c|c|c|c|c|c|c|c|c|c|}
\hline \multirow[b]{3}{*}{ Segment } & \multicolumn{16}{|c|}{ Mean Values of Fundamental Frequency (Hz) } \\
\hline & \multicolumn{4}{|c|}{ Onset } & \multicolumn{4}{|c|}{ Maximum } & \multicolumn{4}{|c|}{ Minimum } & \multicolumn{4}{|c|}{ Offset } \\
\hline & Mip & $M n p$ & $t$ & $p$ & Mip & $M n p$ & $t$ & $p$ & Mip & $M n p$ & $t$ & $p$ & Mip & $M n p$ & $t$ & $p$ \\
\hline Sentence & 242 & 236 & 1.72 & .19 & 342 & 328 & 2.06 & .15 & 140 & 149 & 4.68 & .03 & 211 & 202 & 0.80 & .37 \\
\hline Beginning & 238 & 237 & 0.01 & .93 & 263 & 254 & 2.88 & .09 & 210 & 206 & 1.27 & .26 & 231 & 223 & 4.99 & .03 \\
\hline Ending & 205 & 208 & 0.48 & .49 & 253 & 243 & 2.39 & .12 & 150 & 163 & 10.9 & .00 & 189 & 185 & 0.52 & .47 \\
\hline
\end{tabular}

Significant effects are marked in italics. Mip $=$ mean values for ironic prosody; $\mathrm{Mnp}=$ mean values for normal prosody. 
Table 4. Results from Acoustic Analyses of the Experimental Material for Differences in Intensity (dB)

\begin{tabular}{|c|c|c|c|c|c|c|c|c|c|c|c|c|c|c|c|c|}
\hline \multirow[b]{3}{*}{ Segment } & \multicolumn{16}{|c|}{ Mean Values of Intensity (dB) } \\
\hline & \multicolumn{4}{|c|}{ Onset } & \multicolumn{4}{|c|}{ Maximum } & \multicolumn{4}{|c|}{ Minimum } & \multicolumn{4}{|c|}{ Offset } \\
\hline & Mip & $M n p$ & $t$ & $p$ & Mip & $M n p$ & $t$ & $p$ & Mip & $M n p$ & $t$ & $p$ & Mip & $M n p$ & $t$ & $p$ \\
\hline Sentence & 68 & 69 & 0.85 & .35 & 80 & 80 & 0.82 & .36 & 64 & 65 & 5.30 & .02 & 63 & 64 & 4.78 & .03 \\
\hline Beginning & 68 & 69 & 0.85 & .36 & 77 & 77 & 0.20 & .65 & 67 & 68 & 1.38 & .24 & 71 & 72 & 3.66 & .05 \\
\hline Ending & 68 & 69 & 5.26 & .02 & 75 & 76 & 2.85 & .09 & 64 & 65 & 3.75 & .05 & 63 & 64 & 4.62 & .03 \\
\hline
\end{tabular}

Significant effects are marked in italics. Mip $=$ mean values for ironic prosody; Mnp $=$ mean values for normal prosody.

correct and half were incorrect. Responses were given via a button press. Before the actual experiment started, participants received instructions and a short training of 10 trials.

For experimental presentation, the stimulus material was pseudorandomized and divided into four-item versions of 120 items each. In this way, each experimental item was only presented once within each version. Experimental conditions were equally divided across all versions (i.e., 30 items for each condition). A trial sequence started with the auditory presentation of a discourse (approximately $13.3 \mathrm{sec}$ ) during which a fixation cross was presented in the middle of the computer screen. This fixation cross was presented in white for the first $8000 \mathrm{msec}$ and turned red for the auditory presentation and an additional interval of 1500 msec. Subjects were instructed to avoid moving their eyes during the appearance of the red fixation cross. When this cross disappeared, subjects had to perform the comprehension task. Soon after the response was given (within a period of $6000 \mathrm{msec}$ ) and an intertrial interval of $1000 \mathrm{msec}$, the next trial started. "Yes" and "no" answers were completely balanced across all four experimental conditions, ensuring that neither task nor decision-related expectancy was induced.

\section{Data Recording and Analysis}

Accuracy rates are reported for the behavioral performance, and were used for ERP evaluation. For the statistical analysis of accuracy rates, a repeated measures ANOVA with the factors context (ironic/literal) and prosody (ironic/ normal) was calculated. Whenever interactions were found, further analyses were carried out.

The EEG was recorded continuously using $52 \mathrm{Ag}-\mathrm{AgCl}$ electrodes, ${ }^{4}$ which were referred to the left mastoid, embedded in an elastic cap. Bipolar horizontal and vertical EOG was recorded. Electrode resistance was kept under $5 \mathrm{k} \Omega$. The signals were recorded continuously with a band pass between DC and $70 \mathrm{~Hz}$ and digitized at $250 \mathrm{~Hz}$. Average ERPs were computed for the critical word (i.e., at sentence-final position) for each electrode position in each of the four experimental conditions. All averages started $200 \mathrm{msec}$ before and lasted $1000 \mathrm{msec}$ after the critical event. Only correctly answered trials were included in the average. Approximately 5\% of the trials were excluded from the averages due to ocular artifacts (EOG rejection $\pm 40 \mu \mathrm{V}$ ). Averages were aligned to a 200-msec prestimulus baseline.

For statistical analysis of potential ERP effects, the 300 $500 \mathrm{msec}$ latency window comprising the $\mathrm{N} 400$ component and the 500-900 msec latency range for a potential late positivity effect were chosen. All dependent variables were quantified using multivariate analyses of variance. The multivariate approach to repeated measurements was used to avoid problems concerning sphericity (Dien \& Santuzzi, 2005; Vasey \& Thayer, 1987). For distributional ERP analyses, two topographical factors, anterior/posterior and region of interest (ROIs), were defined and completely crossed, yielding 14 different ROIs each containing three electrodes (see Figure 1). Within-subject factors were anterior/posterior (2), ROI (7), context (2), and prosody (2).

\section{Results}

\section{Behavioral Data}

Participants showed excellent performance on the comprehension task. Accuracy rates were equally divided across all four conditions. The mean accuracy rate was 95.3\% ( $S D=$ 3.40). Statistical analysis did not show significant differences $[F(1,39)<1.73, n s]$.

\section{Electrophysiological Data}

As can be seen in Figure 2, ERPs at the target sentence offset revealed a centro-parietally distributed P600, which was larger for critical words pointing to an ironic rather than a literal interpretation. Most interestingly, an increased N400 for irony was not seen. At the most left anterior electrode sites, a sustained negativity seemed to be evoked by ironic sentences. With regard to an effect of prosody, no differences were seen in ERPs for ironic and normal prosody at the sentence-final word.

Within the N400 time window of 300-500 msec, statistical analysis revealed a three-way interaction of anterior/ posterior, ROI, and context $[F(6,34)=2.90, p<.05]$. Separate analyses for anterior and posterior sites showed an interaction of ROI with context anteriorly $[F(6,34)=3.03$, $p<.05]$, but not posteriorly $[F(6,34)=1.33, n s]$. Further 


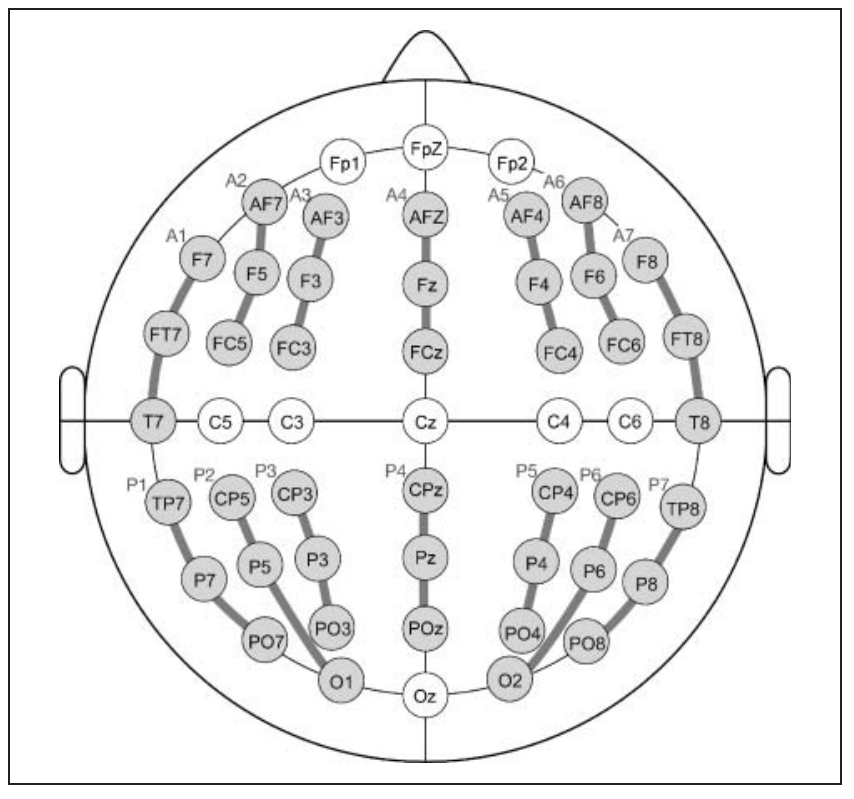

Figure 1. Electrode configuration of the ROIs used for statistical analysis. subanalyses for each anterior ROI revealed a marginally significant effect of context in the most left anterior ROI, namely, A1 $[F(1,39)=3.69, p<.1]$, but not in any other ROIs $[F(1,39)<1.09, n s]$. This confirms the observation that, in response to irony, no N400 component was elicited. However, a left anterior negativity emerged for ironic sentences. With respect to an effect of prosody, statistical analysis revealed neither an interaction nor a main effect of prosody $[F(1,39)<0.66, n s]$.

The statistical analysis for the 500-900 msec time window showed a three-way interaction of anterior/posterior with ROI and context $[F(6,34)=5.22, p<.001]$. Based on this interaction, anterior and posterior electrode sites were analyzed separately. The follow-up analysis for posterior sites revealed a main effect of context $[F(1,39)=6.53$, $p<.01]$, indicating an irony-related P600 component that displayed a centro-parietal scalp distribution. The analysis of the anterior sites showed another interaction between ROI and context $[F(6,34)=5.55, p<.001]$. Further analyses for each anterior ROI separately revealed a main effect of context $[F(1,39)=4.60, p<.05]$ for the most left
Figure 2. Grand-average ERPS elicited by sentence-final words that indicated a nonironic sentence meaning (blue line) or an ironic meaning (red line) with respect to the foregoing discourse context. The acoustic onset of the critical word is at 0 msec on the $x$-axis. In this and all subsequent figures, negativity is plotted upward. The topographic map on the right side shows the scalp distribution of the ERP effects in response to irony.

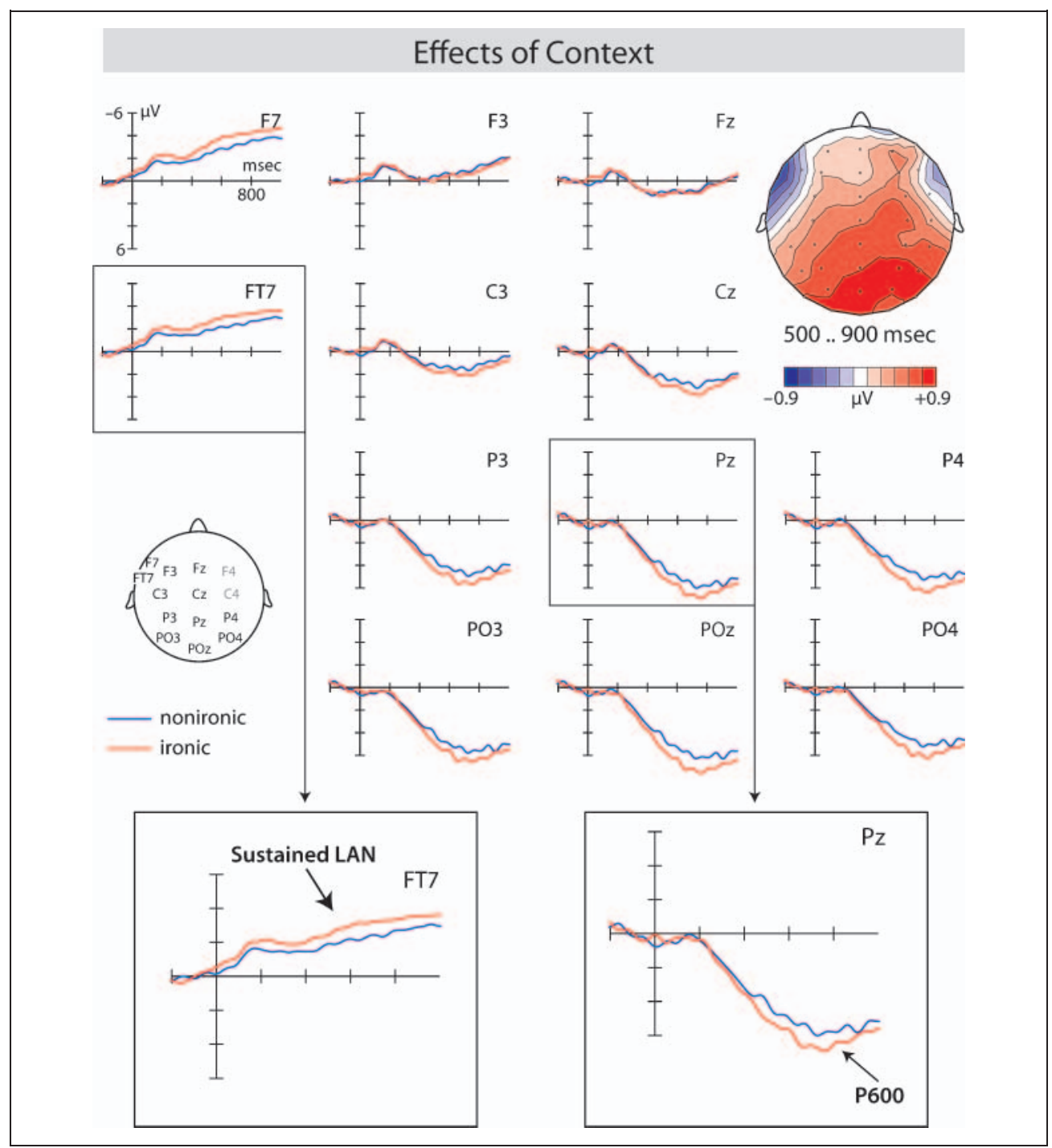


anterior ROI (i.e., A1). This result suggests that the left anterior negativity seen for irony was a long-lasting effect.

With regard to the left anterior negativity, a timeline analysis was carried out to determine the latency onset. Therefore, four consecutive time windows of $50 \mathrm{msec}$ each, beginning at $100 \mathrm{msec}$, were analyzed (i.e., 100-150 msec, 150-200 msec, 200-250 msec, 250-300 msec). Significant three-way interactions of context with anterior/posterior and ROI were found in the time windows of 150-200 msec, 200-250 msec, and 250-300 msec $[F(6,34)=2.31-3.25$, $p<.05]$. Follow-up analyses for anterior sites only showed a further interaction between context and ROI in the 250300 msec time window $[F(6,34)=4.32, p<.002]$. Resolving this interaction revealed a main effect of context in the most left anterior ROI, namely, A1 $[F(1,39)=4.28, p<$ $.05]$, which shows that the left anterior negativity had its onset around $250 \mathrm{msec}$ poststimulus onset.

\section{Discussion}

In Experiment 1, the comprehension of irony in relation to prosodic information was investigated by means of evoked potentials. ERPs measured at the target sentence offset revealed a differential pattern of brain activity for the processing of ironic sentences compared to their literal equivalents. At this sentence position, critical words (e.g., "fantastic") were presented that pointed either to an ironic or literal sentence interpretation. In response to irony, a sustained left anterior negativity starting around $250 \mathrm{msec}$ (which is referred to as sustained LAN) and an additional late posterior positivity were elicited. As this positivity resembled a P600 component in its electrophysiological characteristics (i.e., showing a latency onset of about 500 msec poststimulus presentation with an amplitude maximum over centro-parietal sites), it is classified as a P600 effect. Most importantly, the processing of irony did not result in a larger N400 amplitude. Moreover, comprehension of irony appeared to be uninfluenced by the different prosodic characteristics. At the sentence-final position, only main effects of context were found, but there were no interactions of context with prosody. With regard to the behavioral data, the results showed excellent performance across all conditions implying that figurativity of sentences had no influence on the overall comprehension of the items. The ERPs revealed a more fine-grained picture.

There was no increased N400 associated with irony, which implies that difficulty with semantic integration of the sentence-final word into the foregoing context was not present. The amplitude of the N400 has been shown to be modulated by the ease of semantic integration, and to increase with the difficulty of word integration into foregoing contexts during the processing of literal language (Friederici, Steinhauer, \& Frisch, 1999; Van Petten, Coulson, Rubin, Plante, \& Parks, 1999). The present results indicate that semantic information processing is not more demanding for ironic relative to literal language The absence of an irony-related N400 speaks against the occurrence of semantic incompatibility during the processing of irony.

However, the comprehension of irony is not without effort, as indicated by the early onset of a sustained LAN and the P600. The sustained LAN is an interesting finding as its latency onset around $250 \mathrm{msec}$ poststimulus shows that ironic and literal sentences already diverged at an early phase of processing. The early negativity displayed a left anterior scalp distribution, and resembled sustained LAN effects related to processes of working memory (e.g., Vos, Gunter, Kolk, \& Mulder, 2001; King \& Kutas, 1995; Kluender \& Kutas, 1993). Comparable sustained effects have been reported for the comprehension of humorous sentences, and have been linked to extra processing costs of conceptual-semantic reanalysis that enable shifting from one frame into another (Coulson \& Lovett, 2004; Coulson \& Kutas, 2001). Retrieving new information from long-term memory and reorganizing existing information into a new frame has been proposed to cause increased working memory processes reflected in larger LAN amplitude (Coulson \& Kutas, 2001). Similarly, an increased demand on working memory might be reflected in the sustained LAN observed for irony processing in the present experiment. Sentences containing an ironic meaning might have resulted in processing costs concerning the comprehension of implied meanings. Whether this sustained LAN in response to irony is a reliable effect needs further testing and will be addressed in Experiment 2.

Interestingly, a P600 component in the absence of an N400 was observed for the processing of irony. "Semantic P600 effects" have been reported for thematic role violations (Hoeks et al., 2004; Kuperberg, Sitnikova, et al., 2003), or semantic reversal anomalies (van Herten et al., 2005; Kolk et al., 2003). In a study by Kuperberg, Holcomb, et al. (2003), pragmatically anomalous sentences elicited an enhanced P600 which was, however, preceded by an N400 component. The modulation of the P600 as a function of interacting semantic and syntactic anomalies was found by Gunter et al. (1997, 2000).

At this point, the functional interpretation of the current P600 remains speculative. One interpretation may be that the P600 evoked by irony indeed reflects comprehension processes at a pragmatic or conceptual level. Because different types of information need to be integrated, the P600 might be a function of late integration processes of semantic and extralinguistic information (cf. Lattner \& Friederici, 2003). Alternatively, the requirements of the experimental task might have contributed to the emergence of P600 (see Hahne \& Friederici, 2002; Coulson et al., 1998). In a study by Kolk et al. (2003), for instance, an enhanced P600 was elicited when participants were required to judge the acceptability of sentences whereas no such effect was found in absence of task demands. With regard to the current P600 seen for irony, it may be possible that the comprehension task used in this study yielded similar effects. The overall comprehension of discourse was insured by means of a content question 
that had to be judged for correctness. Although this task involved no overt evaluation of sentences, participants possibly focused more intensively on discourse contexts because this information was task critical.

Another alternative is that the observed P600 could have been caused by strategic processing as targets but not fillers were presented. ${ }^{5}$ Participants might have paid attention to discourse contexts as potential predictors for respective sentence interpretations. Based on prior contextual information and a balanced number of ironic and literal sentences, predictions for respective sentence interpretations might have been generated. Thus, a second experiment was performed to dissociate these two alternatives in terms of the role of experimental task and strategic processing on irony comprehension.

With respect to an impact of prosody on the processing of irony, the absence of an interaction of prosody with context implies that prosodic information provided no influential cue for appropriate interpretations, at least in the present items. Although ironic and normal prosody varied in pitch and duration, it seems that these prosodic characteristics were less reliable for detecting ironic language. The absence of an interaction between prosody and irony might have resulted from the great variability of prosodic features accompanying irony (see Rockwell, 2000, 2007; Anolli et al., 2000). Because target sentences in the current study were presented with both ironic and normal prosody, the function of prosodic characteristics in cueing particular meanings was possibly even more difficult to detect. To specify the exact role of prosody, further research systematically varying prosodic features is necessary to scrutinize potential effects on figurative language comprehension. As the main objective was to validate the generalizability of ERPs seen for irony, Experiment 2 examines the processing of ironic language in addition to potential effects of the task and probability of the occurrence of irony in the visual mode.

\section{EXPERIMENT 2}

The results of Experiment 1 imply that the comprehension of irony does not involve processing difficulty reflected in the N400, but rather in a P600 component. Whether this ERP pattern is reliably evoked by irony (i.e., independent of presentation mode) is investigated in Experiment 2. In addition, this study aims to evaluate effects of task as well as the high frequency with which irony occurred in Experiment 1 . The probability of irony was reduced to reflect a more naturalistic language where irony occurs less frequently than literal language.

To scrutinize how far the requirements of the comprehension task contributed to the emergence of P600, a block design consisting of two experimental blocks was employed, which allowed a comparison of the ERPs for taskdependent versus task-independent processing of irony. In the first block, participants were required to read stimuli for comprehension only. To ensure that they still paid attention to the stimulus material, a posttest recognition task was included upon completion of this block. In the second block, a comprehension task was implemented as used in Experiment 1. The order of the blocks was not balanced to avoid biases of task on stimulus processing during the task-independent block. In the case that the emergence of an irony-related P600 is unaffected by task demands, a comparable late positivity is predicted for irony in the absence of a comprehension task. Interactions between the factors context and task should not be obtained.

Regarding the occurrence of strategic processing, Experiment 2 included filler items that impeded predictions of particular sentence meanings on the basis of the context. In consequence, irony had a lower probability of occurrence (i.e., 30\%) than literal language. Hence, it might be possible that an "oddball" P300 is seen for irony, as this component is modulated by unexpected and rare events (see e.g., Ruchkin, Johnson, Canoune, Ritter, \& Hammer, 1990; Pritchard, 1981). In the case that the irony-related $\mathrm{P} 600$ varies with the manipulation of probability of occurrence, this may challenge the functional significance of this effect. If a similar P600 is obtained as in Experiment 1, this would provide evidence of a strategy-independent processing. Moreover, such a finding would suggest that the ironyrelated P600 is indeed associated with figurative language comprehension, and is not a function of more general processes reflected in the P300.

\section{Methods}

\section{Participants}

Thirty $(15$ women, mean age $=24.6$ years, $S D=2.61$ ) native German-speaking students participated in the experiment. All participants were right-handed, and had normal or corrected-to-normal vision, and were paid for their participation.

\section{Stimulus Material}

Stimuli were the same as used in Experiment 1 with the exception of $30 \%$ new items. ${ }^{6}$ Average cloze probability of all experimental items was $91.8 \%(S D=8.15)$. Sentence-final words of ironic sentences were less expected (i.e., approximately 8\%) than those of literal sentences [paired $t$ test on items: $t(119)=7.31, p<.0001$ ] . An additional pretest on sentence acceptability was performed to control for differences in appropriateness between ironic and literal sentences. In the pretest, 20 participants (10 women, mean age $=23.6$ years, $S D=2.72$ ), who did not take part in the cloze test, read the target sentences in relation to respective discourse contexts, and were asked to evaluate each target sentence on its degree of acceptability in these contexts. Note that all items were divided in two lists so that each participant saw only one version of the target sentences. Sentence acceptability had to be rated on a 5-point scale ( 1 for less acceptable, 5 for highly acceptable), or to be judged as unacceptable. Average acceptability 
of the stimuli was $3.7(S D=0.41)$. Ironic and nonironic sentences did not differ in acceptability [paired $t$ test on items: $t(119)=1.22, n s]$.

The set of 120 experimental items was extended by 60 filler items. These fillers were similar to the ironic items, but ended in a nonironic remark that corresponded with the discourse context and did not contradict it. Thus, on the basis of contextual information, an upcoming ironic or literal remark could not be anticipated. All 120 items and 60 fillers were pseudorandomized and distributed over two lists. Each target sentence occurred only once. Both lists were divided into two blocks containing 60 experimental and 30 filler items each.

\section{Procedure}

In contrast to Experiment 1, experimental items were presented visually. Discourse contexts were shown in one block of three lines on a computer screen in front of the participants. After reading the contexts, participants were instructed to press a button to continue with the presentation (automatic continuation after $20 \mathrm{sec}$ ). Target sentences were presented word-by-word. Presentation onset was introduced by the occurrence of a fixation cross for $200 \mathrm{msec}$ at the center of the screen. Each word appeared in a rapid serial visual presentation mode for 300 msec and was succeeded by a blank screen for 200 msec. Word length was always kept within $2^{\circ}$ of the visual field. All words were presented in light gray on a dark background. After sentence offset, the screen remained blank for 1500 msec. In the task-dependent block (i.e., Block 2), the blank screen was followed by the comprehension task. No such task was employed during Block 1, in which participants were only asked to attentively read the stimuli and not to blink during the word-by-word presentation. After completion of this block, participants were required to complete a posttest questionnaire in which they had to recognize some items of the stimuli presented before. At the beginning of each block, participants received a short training of five trials to familiarize them with the experimental procedure.

\section{Data Acquisition and Analysis}

The data acquisition and analysis were identical to that of Experiment 1. The experimental factors were context (ironic/literal) and task (with/without task). Behavioral data from the second block were analyzed using a paired $t$ test. ERP rejections due to ocular or technical artifacts comprised approximately $8 \%$ of all trials.

\section{Results}

\section{Behavioral Data}

For the second block, which comprised the comprehension task, participants showed excellent performance.
The mean accuracy rate was $96.0 \%(S D=3.20)$. Accuracy rates were equally divided across both conditions. The statistical analysis revealed no significant difference $[t(29)=$ $0.64, n s]$.

\section{Electrophysiological Data}

As displayed in Figures 3 and 4, ERPs showed a slightly increased P200 and a large late positivity in response to irony. The late positive shift was present for irony in both experimental blocks. As in Experiment 1, an irony-related N400 effect was not seen. In the absence of the comprehension task, ERPs for both ironic and literal sentences were more positive in relation to the presence of task demands (see Figure 4).

Statistical analyses of the 200-300 msec latency window showed a marginally significant effect of context $[F(1$, $29)=3.27, p<.1]$, which indicates an increased P200 for ironic compared to literal sentences. An interaction between context and task was not revealed $[F(1,29)=1.38$, $n s]$. An effect of task $[F(1,29)=5.89, p<.05]$, as well as an interaction of task with ROI $[F(6,24)=5.49, p<$ .001], was also found. Resolving this interaction by ROI showed main effects of task over central and right lateral ROIs, namely, R4-R7 $[F(1,29)=5.97-10.21, p<.05]$. In the absence of the comprehension task, an early starting positivity emerged.

In the latency window of 300-500 msec, an effect of task $[F(1,29)=15.55, p<.001]$ and an interaction of task with anterior/posterior and ROI $[F(6,24)=6.62, p<.001]$ was significant. Separate analyses for anterior and posterior sites showed interactions of task with ROI for both sites $[F(1,29)=4.15-6.98, p<.01]$. Further subanalyses for anterior ROIs were carried out, and showed main effects of task in central and right lateral anterior ROIs, namely, A3-A7 $[F(1,29)=4.07-28.54, p<.05]$. Subanalyses for posterior ROIs revealed main effects of task in central and right lateral posterior ROIs, namely, P3-P7 $[F(1,29)=9.53-$ $18.70, p<.01]$. The early starting positivity obtained in the absence of the comprehension task appeared to be a more sustained effect that was still present between 300 and $500 \mathrm{msec}$ and displayed a broad distribution over fronto-central, centro-parietal, and right temporal scalp sites. With regard to the processing of irony, a marginally significant effect of context was found $[F(1,29)=2.99$, $p<.1$ ], indicating a more positive ERP deflection for ironic sentences. An irony-related N400 was not elicited. Moreover, the processing of both ironic and literal sentences appeared to be independent of task because an interaction between context and task was not obtained $[F(1$, 29) $=0.23, n s]$.

The analysis in the 500-900 msec latency range revealed effects of context $[F(1,29)=20.81, p<.0001]$ and task $[F(1,29)=23.81, p<.0001]$. Three-way interactions between context, anterior/posterior, and ROI $[F(6,24)=$ 2.63, $p<.05]$, as well as between task, anterior/posterior, 
Figure 3. Grand-average ERPs measured at the sentence-final word that pointed to a nonironic interpretation (blue line) or an ironic interpretation (red line) with regard to prior discourse contexts. The visual onset of critical words was at 0 msec on the $x$-axis. The map on the right side shows the topographic distribution of the P600 component related to irony.

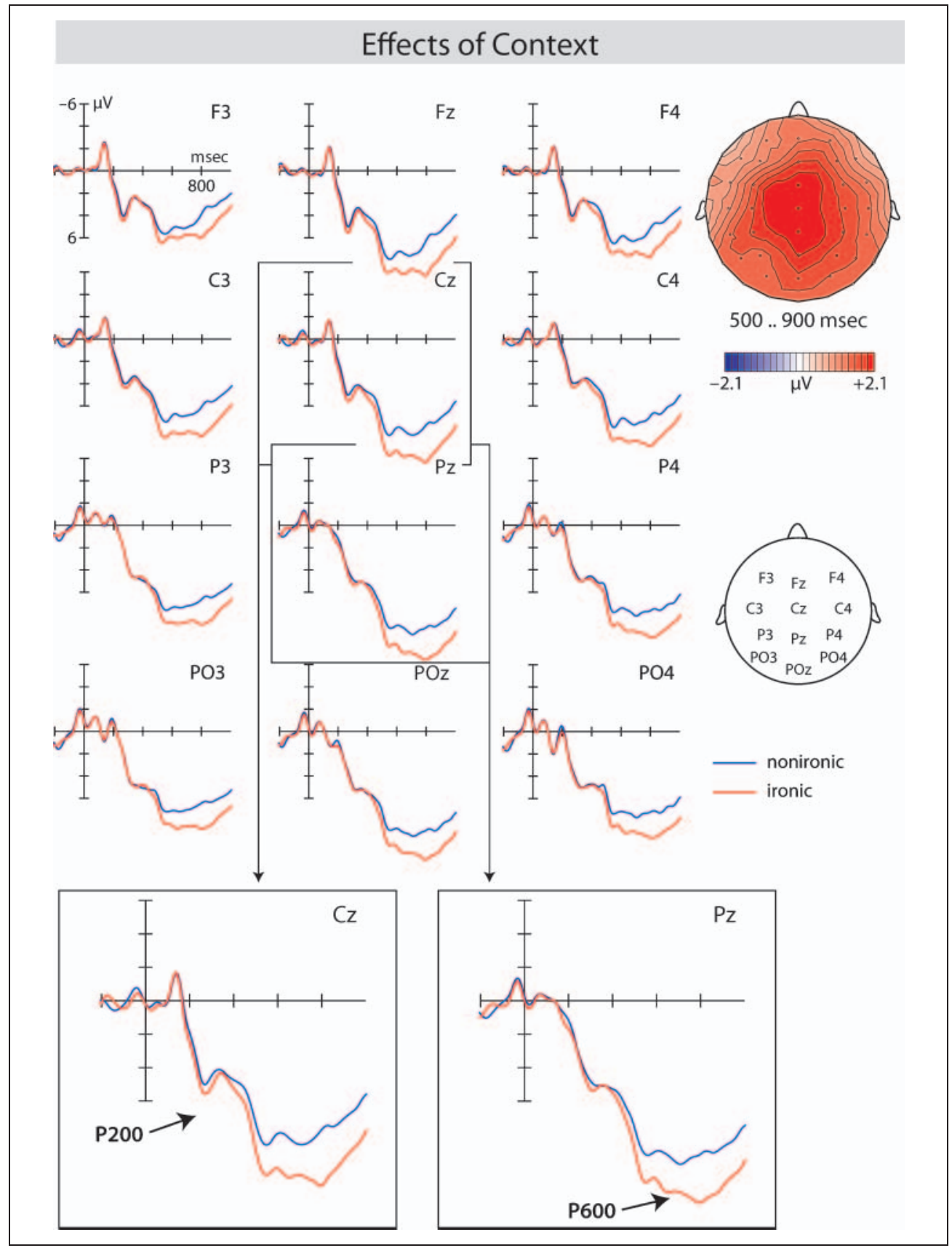

and ROI $[F(6,24)=5.09, p<.01]$, were significant. Resolving both three-way interactions by anterior/posterior showed further interactions of context with ROI $[F(6$, $24)=3.57-3.61, p<.01]$, and task with ROI $[F(6,24)=$ $2.80-6.83, p<.05]$ for anterior and posterior sites. These two-way interactions were resolved by separate analyses for anterior and posterior ROIs. Significant effects of context were revealed for all anterior and posterior ROIs $[F(1$, $29)=5.85-29.85, p<.05]$, replicating the late positivity for ironic sentences. With respect to an effect of task, statistical analyses showed main effects of task for central and right lateral anterior ROIs, namely, A4-A7 $[F(1,29)=6.13-$ $38.02, p<.05]$, as well as for all posterior ROIs $[F(1,29)=$ 10.69-29.85, $p<.01]$. Thus, the positivity evoked in the absence of the comprehension task appeared to be a longlasting effect (already starting at approximately $200 \mathrm{msec}$ ), which displayed a widespread scalp distribution. As shown in the earlier latency windows, an interaction between context and task was not found $[F(1,29)=0.02$, ns $]$. The findings substantiate the observation that the processing of irony was unaffected by task demands.

\section{Discussion}

The present experiment aimed to examine whether the ERPs seen for irony can be generalized across presentation modalities, and explored whether the irony-related P600 seen in Experiment 1 was modulated by task demands or 
strategic processing. Behavioral data measured for the second block again showed that participants' understanding of all discourse instances was excellent. The current ERP data show that a P600 component in the absence of an N400 is a reliable pattern for the comprehension of irony irrespective of presentation modality. Moreover, this P600 effect was unaffected by the presence of the comprehension task as no interactions between context and task were found.

The results suggest that the $\mathrm{P} 600$ is indeed related to the processing of pragmatic information rather than to task requirements. Although the comprehension task primarily demands attentive reading of the discourse contexts, the requirements of this task did not affect the processing of irony. The observation of a task-independent P600 is in accordance with previous ERP studies reporting similar effects (e.g., Kolk et al., 2003; Osterhout, McKinnon, Bersick, \& Corey, 1996; Hagoort, Brown, \& Groothusen, 1993). Yet, in the absence of task demands, the ERPs were more positive (first experimental block) than in the presence of the comprehension task (second experimental block), showing that the overall processing of the stimuli was somehow influenced by task. One speculative explanation for this effect might be that participants' attention was drawn away from foregoing discourse contexts, possibly leading to a more intensive processing of the target sentences during

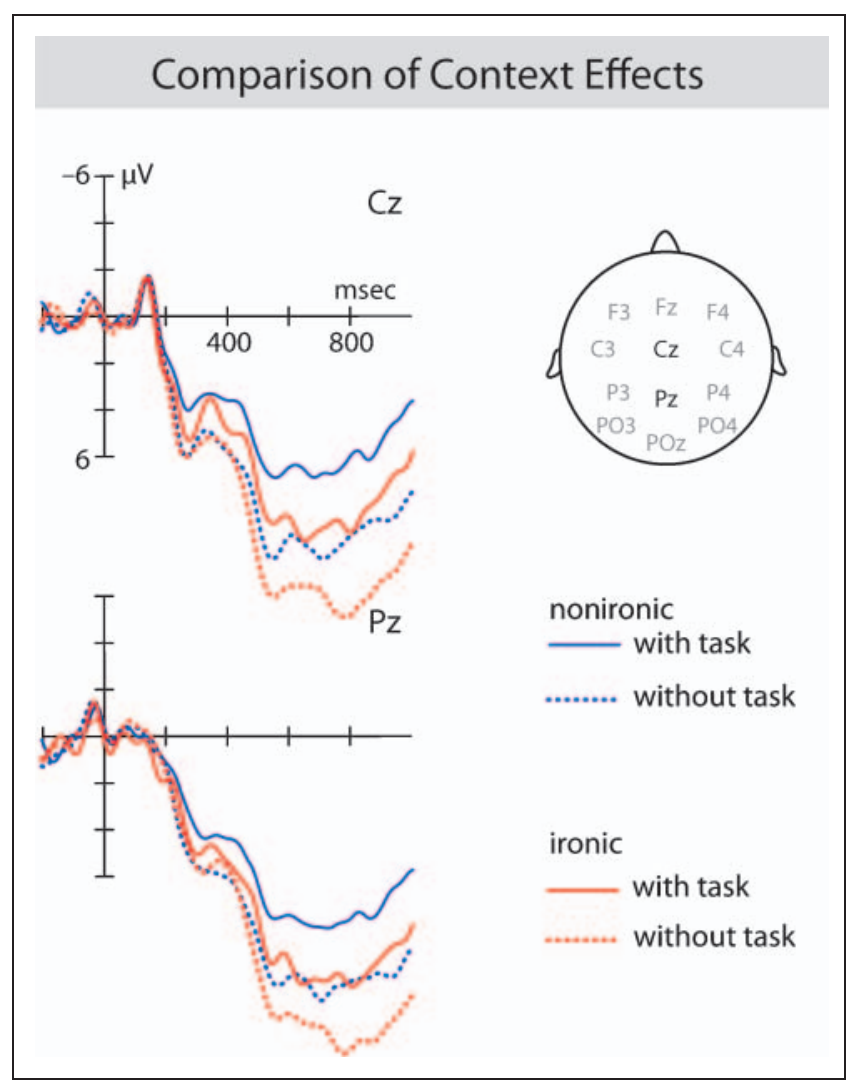

Figure 4. Grand-average ERPs to sentence-final words when participants had to perform the subsequent comprehension task (solid line) or when no such task was performed (dotted line). the task-independent block. Most importantly, the current data also imply that the presence of the P600 effect did not result from strategic processing, as this effect could be replicated for irony even though predictions for particular sentence interpretations were not possible (i.e., due to the presence of fillers). This finding confirms the suggestion that the observed $\mathrm{P} 600$ indeed reflects irony processing. Further, the $\mathrm{P} 600$, in response to irony, did not differ remarkably in latency and morphology, indicating that this effect was not markedly modulated by the lower probability of irony occurring (i.e., 30\%). Interestingly, the irony-related P600 seems to differ from the syntax-related P600. The P600 seen for syntactic anomalies has been shown to vary as a function of task requirements (Hahne \& Friederici, 2002) as well as probability of syntactic anomaly (Hahne \& Friederici, 1999), which is not the case for the P600 in response to irony. The present result, moreover, shows that this ERP response was unaffected by the probability of irony, suggesting a different sensitivity than the domain-general P300 (see Donchin, 1981). By implication, the irony-related P600 most likely reflects comprehension processes involved in figurative language processing as modulations of this ERP component by manipulation of task demands and strategic processing were not seen.

Compared to the findings of Experiment 1, differences in the ERPs were seen with respect to early components. Instead of a sustained LAN, an increased P200 for irony relative to literal language was found in Experiment 2. The absence of a sustained LAN was unexpected because the presentation mode (visual presentation), but not the experimental material (the type of irony), was altered. In Experiment 1, this sustained LAN was suggested to reflect an increased load on working memory associated with the comprehension of implied meanings. However, this effect was not present for irony presented visually, which implies that visual presentation of the stimuli seems to affect early comprehension processes in some way. Although speech perception is continuous and fleeting, self-paced reading in Experiment 2 possibly resulted in a more in-depth context processing (possibly by rereading text passages), making an upload of working memory resources unnecessary during irony comprehension. In addition, in Experiment 2, the probability of irony occurrence and the experimental setting regarding the block design was manipulated. However, these factors are unlikely to have caused early differences in the ERPs seen for Experiment 2. For the probability of stimulus occurrence, comparable P200 effects have not been reported in the literature. Moreover, no interactions between context and task were found, indicating that the task manipulation (employed by the block design) did not affect early comprehension processes. Nevertheless, an increased P200 was seen for ironic language, suggesting that, already at around $200 \mathrm{msec}$ poststimulus, the processing of irony differs from that of literal language. As this P200 was marginal, and occurred only in the visual domain, its functional significance cannot be clearly defined. 
With regard to the literature, it may be speculated whether P200 reflects an extended early semantic analysis of critical words indicating irony. Although such processes were often induced by semantic categorization tasks (e.g., Landi \& Perfetti, 2007), they might have been initiated by foregoing discourse contexts, particularly for irony. Ironic contexts pointed to a disapproving utterance that contradicted the semantic (literally positive) meaning of critical words. Evidence of early context effects stems from ERP studies indicating that retrieval of lexical-semantic information can already occur 200 msec after stimulus onset (Penolazzi, Hauk, \& Pulvermüller, 2007; Martin-Loeches, Hinojosa, Casado, Munoz, \& Fernandez-Frias, 2004; Hagoort \& Brown, 2000). As these studies reported modulations of different ERP components, further evidence is necessary to substantiate a sensitivity of $\mathrm{P} 200$ to aspects of semantic information processing on the sentence level.

\section{GENERAL DISCUSSION}

The aim of these two experiments was to investigate the neurocognitive mechanisms underlying the comprehension of irony, and to explore the timing of irony processing. We examined whether encountering irony requires effortful semantic processing as reflected by an increased N400, and whether it involves additional cognitive processes during sentence interpretation as possibly reflected by the P600 component. We presented two types of discourses ending in an identical sentence (e.g., "These artists are fantastic"), whose interpretation as ironic or literal was dependent on the foregoing context. The final word in the target sentence conveyed critical information for respective interpretations. In both the acoustic (Experiment 1) and visual (Experiment 2) presentation modes, sentences with an ironic meaning (compared to literal sentences) elicited early ERP effects and a larger P600 amplitude. The results provide evidence of the engagement of distinct cognitive processes during early and late stages of processing. An irony-related N400 component was not observed, suggesting that the processing of irony caused no semantic integration difficulty. Because semantic expectancy was controlled for, a potential N400 effect for ironic sentences would have reflected difficulty in semantic integration.

An impact of prosody on the perception and interpretation of irony was not found. When critical information for sentence meanings becomes available, prosodic characteristics seem to be less relevant compared to semantic information. It is also possible that subtle features of emotional prosody could not be adopted by presenting ironic and literal target sentences with both ironic and normal prosody. Further investigation is needed to identify the basic cause of the absence of an effect of prosody on irony comprehension besides potential effects of differential prosodic marking of irony (cf. Attardo, 2000; Rockwell, 2000).

The two experiments showed that irony, which is literally incongruent with its foregoing context, does not evoke an $\mathrm{N} 400$ when it remains pragmatically plausible (i.e., by achieving a figurative meaning). This finding accords with ERP studies which showed that the preceding context facilitates the integration of words into a coherent discourse representation (Van Berkum, Zwitserlood, Hagoort, \& Brown, 2003; St. George, Mannes, \& Hoffman, 1994). Even if a sentence meaning literally contradicts the preceding context, critical words can easily be integrated when the foregoing information biases toward a particular sentence interpretation. This substantiates the role of context during language comprehension by showing that contextual information is immediately taken into account. However, for complete understanding of implied meanings, additional cognitive processes seemed to be involved during late stages of processing, as shown in the $\mathrm{P} 600$ amplitude.

Recent ERP studies on the comprehension of figurative language (Coulson \& Van Petten, 2002) or jokes (Coulson \& Kutas, 2001) mainly reported N400 effects or combinations of $\mathrm{N} 400$ and $\mathrm{P} 600$, proposing that nonliteral language requires effortful semantic processing. Compared to these studies, the present occurrence of a late positivity in the absence of an N400 suggests that the processing of irony seems to recruit distinct processing mechanisms. The finding that the P600 occurred in both experiments (i.e., independent of task requirements and probability of irony occurrence) indicates that this ERP component is systematically associated with the processing of figurative language. Given that the ironic stimuli used were relatively novel (i.e., not conventional), an appropriate ironic meaning was unlikely to be associated with the word form of the sentence-final word. It is therefore not unreasonable to assume that further information from common world knowledge needs to be retrieved and integrated in order to establish a coherent pragmatic interpretation. Possibly, this process is indexed by the late positivity.

Modulations of $\mathrm{P} 600$ have been reported for anomalies of syntactic or thematic structure, suggesting that this brain potential is sensitive to various aspects of language processing. The current finding of $\mathrm{P} 600$ in response to irony is consistent with ERP studies arguing that this component reflects reintegration of semantic meaning with extralinguistic information (Lattner \& Friederici, 2003). One possible alternative to be considered is that this brain potential might be a function of the processing of emotional information conveyed by irony because ironic instances mainly express a speaker's disappointment at an event. A late positive complex often emerges in response to emotionally arousing pictures and also to emotional (pleasant and unpleasant) words in contrast to neutral words (Kissler, Herbert, Winkler, \& Junghofer, 2009; Herbert, Junghofer, \& Kissler, 2008; Fischler \& Bradley, 2006). Moreover, the late positive complex has typically been linked to task demands such as attention or evaluation biases (see e.g., Kanske \& Kotz, 2007; Fischler \& Bradley, 2006). However, in the current experiments, emotionality was evoked by the target sentences but was not inherent in critical words. Because no evaluation of sentence valence was required, 
emotionality would have been detected implicitly. Moreover, the P600 component was observed for ironic compared to literal sentences, but not compared to neutral items, as typically reported in the literature (see e.g., Kissler et al., 2009). On the basis of the issues discussed, it seems less likely that the P600 seen for irony is a reflection of emotionality. This irony-related brain potential might rather be associated with figurative language comprehension, and possibly reflects pragmatic interpretation of implied sentence meanings.

\section{Implications for Models of Figurative Language Comprehension}

With respect to models of figurative language comprehension, the current data partially support the assumptions of the standard pragmatic model (Searle, 1979; Grice, 1975) and the graded salience bypothesis (Giora, 1997, 1999) regarding the proposed later stages of processing. According to these two models, contextual information affects later stages of processing after the activation of the literal meaning of figurative statements. The finding of an irony-related P600 might imply increased processing costs associated with the pragmatic interpretation of irony. Grice (1975, 1989) assumed that the comprehension of figurative language involves additional inferential processes (i.e., conversational implicature) that enable the construction of contextually appropriate meanings after an incompatibility during the integration of literal meanings has occurred. Although the absence of an N400 implies that a semantic incompatibility phase was not present, an engagement of inferential processes seems to be necessary in resolving the disparity between the literal sentence meaning and the preceding context by which an ironic meaning might be derived (i.e., apparently as indexed by the P600).

The observation of early ERP effects shown by the P200 and sustained LAN is neither consistent with the standard pragmatic model (Grice, 1975) nor the graded salience hypothesis (Giora, 1997, 1999). An impact of contextual information occurring between 200 and $300 \mathrm{msec}$ poststimulus implies that during initial phases of processing, the comprehension of literal and ironic language already diverged. The finding of early modulations of ERPs suggests an involvement of different neurocognitive processes, which contradicts the assumption of an initial activation of the literal or most salient meaning for both ironic and literal sentences as predicted by these two models (see Giora, 1997, 1999; Grice, 1975). What these differences in initial processing are remains unclear as the sustained LAN and P200 seem to be associated with functionally distinct cognitive processes. Further investigation of this issue is necessary.

When all the data are taken into account, it seems clear that the standard pragmatic model (Grice, 1975; Searle, 1979) needs to be revised in terms of the proposed lexicalsemantic processes. Contextual information apparently affects the initial processing of lexical and semantic information, entailing the effortless integration of literal word meanings with the preceding contexts in the case of irony. Similarly, the current findings suggest a revision of the graded salience hypothesis (Giora, 1997, 1999) in terms of the assumed processing of nonsalient figurative sentences. Ironic instances applied in the experiments consisted of nonsalient meanings that are usually not coded in the mental lexicon, and thus, entailed an initial activation of the most salient (i.e., literal) meanings irrespective of contextual constraints or figurativity. As early ERP effects were obtained, this implies that lexical-semantic information processing seems to be affected by prior contextual information. Regarding the direct access view (Gibbs, 1994, 2002), the finding of a P600 component does not confirm the proposed engagement of similar processing mechanisms in figurative and literal language comprehension. The observation of $\mathrm{P} 600$ in response to irony implies that processing ironic utterances was more demanding than literal language. Although target sentences were embedded in rich, supportive contexts, direct comprehension of implied ironic meanings, as assumed by Gibbs (1994, 2002), was apparently not the case. The P600 seen for irony can rather be taken as support for an involvement of additional neurocognitive processes related to pragmatic interpretation during figurative language comprehension.

\section{Conclusion}

Taken together, the most important and novel finding of both experiments is the absence of an N400 component for irony, which suggests that processing figurative meanings does not involve semantic integration difficulty when it is provided with supportive contexts. Thus, during the comprehension of irony, the recognition of a semantic incongruence is not necessary for integrating literal sentence meanings with foregoing contextual information. Instead, irony consistently evoked a P600 component relative to its literal equivalents, showing that additional processing seems to be necessary for interpreting implied ironic meanings. The observation of P600 in response to irony seen in the current experiments provides some support for an involvement of inferential processes during late phases of processing, which accords with the standard pragmatic model (Grice, 1975) and the graded salience hypothesis (Giora, 1997, 1999). Although the derivation of implied ironic meanings seems to require effortful processing, the integration of semantic information appeared to be as easy as for literal language. The current ERP data provide an indication that the tested psycholinguistic models of figurative language comprehension need to be specified with regard to the comprehension of irony.

\section{Acknowledgments}

We thank three anonymous reviewers for their helpful comments. We also thank Sven Gutekunst for his technical support, Cornelia Schmidt and Ina Koch for the data acquisition, and Kerstin Flake for expert advice with the illustrations. 
Reprint requests should be sent to Stefanie Regel, Max-PlanckInstitute for Human Cognitive and Brain Sciences, PO Box 500 355, D-04303 Leipzig, Germany, or via e-mail: regel@cbs.mpg.de.

\section{Notes}

1. Similarly, the constraint satisfaction approach assumes a context-dependent processing based on multiple cues and by means of constraint satisfaction (Pexman, 2008). However, what comprehension processes are involved in deriving an ironic interpretation is not further specified in this approach.

2. Note that there is no clear distinction between sarcasm and verbal irony. Sarcastic utterances are usually defined as a more aggressive form of irony involving a victim to whom the utterance is addressed. However, both forms of ironic language are closely related in the manner of talking and are often used for aiming criticism at an individual or event.

3. Semantic expectancy is measured by a word's cloze probability in a certain context obtained by a cloze test (Taylor, 1953). In such a test, participants are asked to complete a sentence with the first word that comes to mind.

4. Fp1, Fpz, Fp2, AF7,AF3, AFz, AF4, AF8, F7, F5, F3, Fz, F4, F6, F8, FT7, FC5, FC3, FCz, FC4, FC6, FT8, T7, C5, C3, Cz, C4, C6, T8, TP7, CP5, CP3, CPz, CP4, CP6, TP8, P7, P5, P3, Pz, P4, P6, P8, PO7, PO3, POz, PO4, PO8, O1, Oz, O1, and left mastoid. 5. Strategic processing is assumed as an explanation of the P600 effect because participants may have detected these two types of sentence interpretation following a particular kind of discourse context.

6. Note that this study was part of a series of ERP experiments for which some of the target sentences had to be newly created.

\section{REFERENCES}

Anolli, L., Ciceri, R., \& Infantino, M. G. (2000). Irony as a game of implicitness: Acoustic profiles of ironic communication. Journal of Psycholinguistic Research, 29, 275-311.

Attardo, S. (2000). Irony as relevant inappropriateness. Journal of Pragmatics, 32, 793-826.

Attardo, S., Eisterhold, J., Hay, J., \& Poggi, I. (2003). Multimodal markers of irony and sarcasm. International Journal of Humor Research, 2, 243-260.

Bornkessel-Schlesewsky, I., \& Schlesewsky, M. (2008). An alternative perspective on "semantic P600" effects in language comprehension. Brain Research Reviews, 59, $55-73$.

Brown, C., \& Hagoort, P. (1993). The processing nature of the $\mathrm{N} 400$-Evidence from masked priming. Journal of Cognitive Neuroscience, 5, 34-44.

Brown, P., \& Levinson, S. (1978). Universals in language useage: Politeness phenomena. In E. Goody (Ed.), Questions and politeness (pp. 56-311). Cambridge, UK: Cambridge University Press.

Cornejo, C., Simonetti, F., Aldunate, N., Ibanez, A., Lopez, V., \& Melloni, L. (2007). Electrophysiological evidence of different interpretative strategies in irony comprehension. Journal of Psycholinguistic Research, 36, 411-430.

Coulson, S., King, J. W., \& Kutas, M. (1998). Expect the unexpected: Event-related brain response to morphosyntactic violations. Language and Cognitive Processes, 13, 21.

Coulson, S., \& Kutas, M. (2001). Getting it: Human event-related brain response to jokes in good and poor comprehenders. Neuroscience Letters, 316, 71-74.
Coulson, S., \& Lovett, C. (2004). Handedness, hemispheric asymmetries, and joke comprehension. Cognitive Brain Research, 19, 275-288.

Coulson, S., \& Van Petten, C. (2002). Conceptual integration and metaphor: An event-related potential study. Memory $\varepsilon$ Cognition, 30, 958-968.

Coulson, S., \& Van Petten, C. (2007). A special role for the right hemisphere in metaphor comprehension?: ERP evidence from hemifield presentation. Brain Research, 1146, 128-145.

Dews, S., \& Winner, E. (1999). Obligatory processing of literal and non-literal meanings in verbal irony. Journal of Pragmatics, 31, 1579-1599.

Dien, J., \& Santuzzi, A. M. (2005). Application of repeated measures ANOVA to high density ERP datasets: A review and tutorial. In T. C. Handy (Ed.), Event-related potentials: A methods handbook. Cambridge, MA: MIT Press.

Donchin, E. (1981). Surprise...Surprise? Psychophysiology, 18, 493-513.

Ericsson, E., Olofsson, J. K., Nordin, S., Rudolfsson, T., \& Sandstrom, G. (2008). Is the P600/SPS affected by the richness of semantic content? A linguistic ERP study in Swedish. Scandinavian Journal of Psychology, 49, 1-9.

Ferretti, T. R., Schwint, C. A., \& Katz, A. N. (2007). Electrophysiological and behavioral measures of the influence of literal and figurative contextual constraints on proverb comprehension. Brain and Language, 101, 38-49.

Fischler, I., \& Bradley, M. (2006). Event-related potential studies of language and emotion: Words, phrases, and task effects. Understanding Emotions, 156, 185-203.

Friederici, A. D., Gunter, T. C., Hahne, A., \& Mauth, K. (2004). The relative timing of syntactic and semantic processes in sentence comprehension. NeuroReport, 15, 165-169.

Friederici, A. D., Hahne, A., \& Saddy, D. (2002). Distinct neurophysiological patterns reflecting aspects of syntactic complexity and syntactic repair. Journal of Psycholinguistic Research, 31, 45-63.

Friederici, A. D., Steinhauer, K., \& Frisch, S. (1999). Lexical integration: Sequential effects of syntactic and semantic information. Memory and Cognition, 27, 438-453.

Friederici, A. D., \& Weissenborn, J. (2007). Mapping sentence form onto meaning: The syntax-semantic interface. Brain Research, 1146, 50-58.

Gibbs, R. W. (1986). On the psycholinguistics of sarcasm. Journal of Experimental Psychology: General, 115, 3-15.

Gibbs, R. W. (1994). Figurative thought and figurative language. In M. A. Gernsbacher (Ed.), Handbook of psycholinguistics (pp. 411-446). San Diego, CA: Academic Press.

Gibbs, R. W. (2002). A new look at literal meaning in understanding what is said and implicated. Journal of Pragmatics, 34, 457-486.

Giora, R. (1997). Understanding figurative and literal language: The graded salience hypothesis. Cognitive Linguistics, 7, 183-206.

Giora, R. (1999). On the priority of salient meanings: Studies of literal and figurative language. Journal of Pragmatics, 31, 919-929.

Giora, R. (2002). Literal versus figurative language: Different or equal? Journal of Pragmatics, 34, 487-506.

Giora, R., \& Fein, O. (1999). Irony: Context and salience. Metaphor and Symbol, 14, 241-257.

Grice, P. H. (1975). Logic and conversation. In P. Cole \& J. L. Morgan (Eds.), Speech acts: Syntax and semantics (pp. 41-58). New York: Academic Press.

Grice, P. H. (1989). Studies in the way of words. Cambridge, MA: Harvard University Press.

Gunter, T. C., Friederici, A. D., \& Schriefers, H. (2000). Syntactic gender and semantic expectancy: ERPs reveal early autonomy 
and late interaction. Journal of Cognitive Neuroscience, $12,556-568$

Gunter, T. C., Stowe, L. A., \& Mulder, G. (1997). When syntax meets semantics. Psychophysiology, 34, 660.

Hagoort, P., Brown, C., \& Groothusen, J. (1993). The syntactic positive shift as an ERP measure of syntactic processing. Language and Cognitive Processes, 8, 439.

Hagoort, P., \& Brown, C. M. (2000). ERP effects of listening to speech: Semantic ERP effects. Neuropsychologia, 38, $1518-1530$.

Hahne, A., \& Friederici, A. D. (1999). Electrophysiological evidence for two steps in syntactic analysis: Early automatic and late controlled processes. Journal of Cognitive Neuroscience, 11, 194-205.

Hahne, A., \& Friederici, A. D. (2002). Differential task effects on semantic and syntactic processes as revealed by ERPs. Cognitive Brain Research, 13, 339-356.

Herbert, C., Junghofer, M., \& Kissler, J. (2008). Event related potentials to emotional adjectives during reading. Psychophysiology, 45, 487-498.

Hoeks, J. C. J., Stowe, L. A., \& Doedens, G. (2004). Seeing words in context: The interaction of lexical and sentence level information during reading. Cognitive Brain Research, 19, 59-73.

Holtgraves, T. M. (2001). Language as social action: Social psychology and language use. Mahwah, NJ: Erlbaum.

Kaan, E., Harris, A., Gibson, E., \& Holcomb, P. (2000). The P600 as an index of syntactic integration difficulty. Language and Cognitive Processes, 15, 159

Kanske, P., \& Kotz, S. A. (2007). Concreteness in emotional words: ERP evidence from a hemifield study. Brain Research, $1148,138-148$.

King, J. W., \& Kutas, M. (1995). Who did what and when: Using word-level and clause-level ERPs to monitor working-memory usage in reading. Journal of Cognitive Neuroscience, 7 , 376-395.

Kissler, J., Herbert, C., Winkler, I., \& Junghofer, M. (2009). Emotion and attention in visual word processing: An ERP study. Biological Psychology, 80, 75-83.

Kluender, R., \& Kutas, M. (1993). Bridging the gap: Evidence from ERPs on the processing of unbounded dependencies. Journal of Cognitive Neuroscience, 5, 196-214.

Kolk, H. H. J., Chwilla, D. J., van Herten, M., \& Oor, P. J. W. (2003). Structure and limited capacity in verbal working memory: A study with event-related potentials. Brain and Language, 85, 1-36.

Kuperberg, G. R., Holcomb, P. J., Sitnikova, T., Greve, D., Dale, A. M., \& Caplan, D. (2003). Distinct patterns of neural modulation during the processing of conceptual and syntactic anomalies. Journal of Cognitive Neuroscience, 15, 272-293.

Kuperberg, G. R., Sitnikova, T., Caplan, D., \& Holcomb, P. J. (2003). Electrophysiological distinctions in processing conceptual relationships within simple sentences. Cognitive Brain Research, 17, 117-129.

Kutas, M., \& Federmeier, K. D. (2000). Electrophysiology reveals semantic memory use in language comprehension. Trends in Cognitive Sciences, 4, 463.

Kutas, M., \& Hillyard, S. A. (1980). Reading senseless sentences: Brain potentials reflect semantic incongruity. Science, 207, 203-205.

Kutas, M., \& Hillyard, S. A. (1984). Brain potentials during reading reflect word expectancy and semantic association. Nature, 307, 161

Kutas, M., Van Petten, C. K., \& Kluender, R. (2006). Psycholinguistics electrified II (1994-2005). In M. A. Gernsbacher (Ed.), Handbook of psycholinguistics (pp. 659-724). San Diego, CA: Academic Press.
Landi, N., \& Perfetti, C. A. (2007). An electrophysiological investigation of semantic and phonological processing in skilled and less-skilled comprehenders. Brain and Language, 102, 30-45.

Lattner, S., \& Friederici, A. D. (2003). Talker's voice and gender stereotype in human auditory sentence processing: Evidence from event-related brain potentials. Neuroscience Letters, 339, 191-194.

Laurent, J.-P., Denhieres, G., Passerieux, C., Iakimova, G., \& Hardy-Bayle, M.-C. (2006). On understanding idiomatic language: The salience hypothesis assessed by ERPs. Brain Research, 1068, 151-160.

Martin-Loeches, M., Hinojosa, J. A., Casado, P., Munoz, F., \& Fernandez-Frias, C. (2004). Electrophysiological evidence of an early effect of sentence context in reading. Biological Psychology, 65, 265-280.

Nieuwland, M. S., \& Van Berkum, J. J. A. (2005). Testing the limits of the semantic illusion phenomenon: ERPs reveal temporary semantic change deafness in discourse comprehension. Cognitive Brain Research, 24, 691-701.

Osterhout, L., Holcomb, P. J., \& Swinney, D. A. (1994). Brain potentials elicited by garden-path sentences: Evidence of the application of verb information during parsing. Journal of Experimental Psychology: Learning, Memory, and Cognition, 20, 786.

Osterhout, L., McKinnon, R., Bersick, M., \& Corey, V. (1996). On the language specificity of the brain response to syntactic anomalies: Is the syntactic positive shift a member of the $\mathrm{P} 300$ family? Journal of Cognitive Neuroscience, 8, 507-526.

Osterhout, L., \& Mobley, L. A. (1995). Event-related brain potentials elicited by failure to agree. Journal of Memory and Language, 34, 739.

Penolazzi, B., Hauk, O., \& Pulvermüller, F. (2007). Early semantic context integration and lexical access as revealed by event-related brain potentials. Biological Psychology, 74, 374-388.

Pexman, P. M. (2008). It's fascinating research: The cognition of verbal irony. Current Directions in Psychological Science, 17, 286-290.

Pritchard, W. S. (1981). Psychophysiology of P300. Psychological Bulletin, 89, 506-540.

Pynte, J., Besson, M., Robichon, F.-H., \& Poli, J. (1996). The time-course of metaphor comprehension: An event-related potential study. Brain and Language, 55, 293-316.

Rockwell, P. (2000). Lower, slower, louder: Vocal cues of sarcasm. Journal of Psycholinguistic Research, 29, 483-495.

Rockwell, P. (2007). Vocal features of conversational sarcasm: A comparison of methods. Journal of Psycholinguistic Research, 36, 361-369.

Ruchkin, D. S., Johnson, R., Canoune, H. L., Ritter, W., \& Hammer, M. (1990). Multiple sources of P3b associated with different types of information. Psychophysiology, 27, 157-176.

Searle, J. R. (1979). Expression and meaning. Cambridge, UK: Cambridge University Press.

St. George, M., Mannes, S., \& Hoffman, J. E. (1994). Global semantic expectancy and language comprehension. Journal of Cognitive Neuroscience, 6, 70-83.

Tartter, V. C., Gomes, H., Dubrovsky, B., Molholm, S., \& Stewart, R. V. (2002). Novel metaphors appear anomalous at least momentarily: Evidence from N400. Brain and Language, 80, 488-509.

Taylor, W. L. (1953). "Cloze procedure": A new tool for measuring readability. Journalism Quarterly, 30, 415-433.

Van Berkum, J. J. A., Brown, C. M., Hagoort, P., \& Zwitserlood, P. (2003). Event-related brain potentials reflect discourse-referential ambiguity in spoken language comprehension. Psychophysiology, 40, 235-248. 
Van Berkum, J. J. A., Hagoort, P., \& Brown, C. M. (1999). Semantic integration in sentences and discourse: Evidence from the N400. Journal of Cognitive Neuroscience, 11, 657-671.

Van Berkum, J. J. A., Zwitserlood, P., Hagoort, P., \& Brown, C. M. (2003). When and how do listeners relate a sentence to the wider discourse? Evidence from the N400 effect. Cognitive Brain Research, 17, 701-718.

van Herten, M., Kolk, H. H. J., \& Chwilla, D. J. (2005). An ERP study of P600 effects elicited by semantic anomalies. Cognitive Brain Research, 22, 241-255.

van Petten, C., Coulson, S., Rubin, S., Plante, E., \& Parks, M. (1999). Time course of word identification and semantic integration in spoken language. Journal of Experimental
Psychology: Learning, Memory, and Cognition, 25, 394-417.

Vasey, M. W., \& Thayer, J. F. (1987). The continuing problem of false positives in repeated measures ANOVA in psychophysiology: A multivariate solution. Psychophysiology, 24, 479-486.

Vissers, C. T. W. M., Chwilla, D. J., \& Kolk, H. H. J. (2006). Monitoring in language perception: The effect of misspellings of words in highly constrained sentences. Brain Research, 1106, 150-163.

Vos, S. H., Gunter, T. C., Kolk, H. H. J., \& Mulder, G. (2001). Working memory constraints on syntactic processing: An electrophysiological investigation. Psychophysiology, 38, 41-63. 